\title{
Brief Chronological Study of the Evolution of Electrical Discharge Machining - A Review
}

\author{
Vishal Pathania ${ }^{1}$, Narinder Singh Jassal $^{2}$ \\ ${ }^{1}$ Himachal Pradesh Technical University, Mechanical Engineering,Gandhi Chowk, Hamirpur (177001). \\ ${ }^{2}$ Central Scientific Instruments Organisation CSIR, ISTC Chandigah, Sector-30 (160030)
}

\begin{abstract}
Un-conventional or non-traditional machining methods generally create a phantasm in mind that these are very new. In reality these methods are named so because of the process mechanism in which no shear force is used directly neither there is any contact between tool and workpiece. This does not insinuate that these processes are new because 1694 saw the dawn of EDM when Sir Robert Boyle described the phenomena of electric discharges, 1952 saw the birth of electron beam technology andin the year of 1957 and Gordon Gould designed the first laser device. All these non-traditional processes have developed rapidly in last few decades and are now the state of the art of the present manufacturing technology. Among these EDM has accrued a lot because of its advantages over other non-traditional processes. This accruement is result of various unprecedented ideas those changed the countenance of EDM and made it more efficient and economic process among the non-traditional processes. This paper presents the literature survey to throw light on all those ideas those lead to the current state of the art of EDM.
\end{abstract}

Keywords: EDM, dry-EDM, dielectric, electrode modification, review

\section{History}

The bases of EDM were probably established in 1694, when Sir Robert Boyle described the phenomena of electric discharges in a gap. It was then in 1770 when the English Chemist Joseph Priestly discovered the erosive nature of electrical discharge or spark and at that time thoughtand research of machining was very imprecise and riddled with failures.During 1930s, first time V.E. Matulaitis and H.V. Harding of Elox US developed "Disintegrators" to remove broken taps from valuable workpiece materials such as cemented carbide and high speed steel. In 1943 to address to the pitting of the tungsten electrode the USSR Government tasked Dr. Boris Lazarenko and Dr. Natalya Lazarenko of Moscow University and in 1946 they came up with new proposal first of its kind to use spark for machining metals $[1,2]$. In 1950s, control of gap and pulse times between the electrode and workpiece by the RC (resistance capacitance) relaxation circuit was introduced which provided a simple servo control circuit and later helped in successive developments in EDM technology. In 1954 Agie was founded in Switzerland and a company called les Ateliers des Charmilles produced their first machine in 1955.

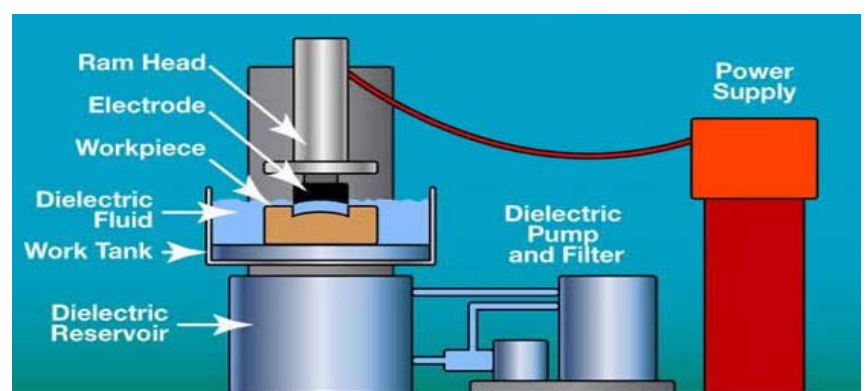

Figure 1: EDM setup

The first EDM machine that used a wire as an electrode became commercially available in 1967 and was developed by USSR and after that WEDM machines that were capable of following lines from drawings were developed by
Andrew Engineering. In mid 1970s, WEDM became a practical and manageable technique when the same company later developed the first Computer Numerical Control (CNC) wire EDM machine in 1976. Since then the unrealistic and impossible EDM process has undergone such a dramatic evolution that today EDM accounts $7 \%$ to the all world machine tool sales.

\section{Working}

EDM can be successfully applied to metals, single-phase ceramics, cermets, and ceramic/matrix composites, as far as they exhibit an electrical resistivity lower than values between 100 and $300 \Omega$-cm [9]. In EDM there is a conducting electrode or tool which is generally immersed in a dielectric which may be liquid or gaseous dielectric. During the machining process the tool moves toward workpiece until the gap distance between the tool and workpiece becomes small enough so that the impressed voltage is enough to ionize the dielectric fluid [9]. This ionization results in the building up of discharge between tool and workpiece. When the value of impressed voltage applied at the electrode and workpiece gap increases to a point then the ions and electrons start to form and they start to align themselves along the shortest distance between the electrode and workpiece. This result in the breakdown of the dielectric strength of the dielectric and under the influence of such an intense electric field a spark is generated and it prevails for the $10^{\text {th }}$ of a micro second. As a result of the decrease of the resistance of the dielectric and bridging effect of the ions and electrons the spark moves toward the workpiece. 


\section{International Journal of Science and Research (IJSR) \\ ISSN (Online): 2319-7064}

Index Copernicus Value (2015): 78.96 | Impact Factor (2015): 6.391

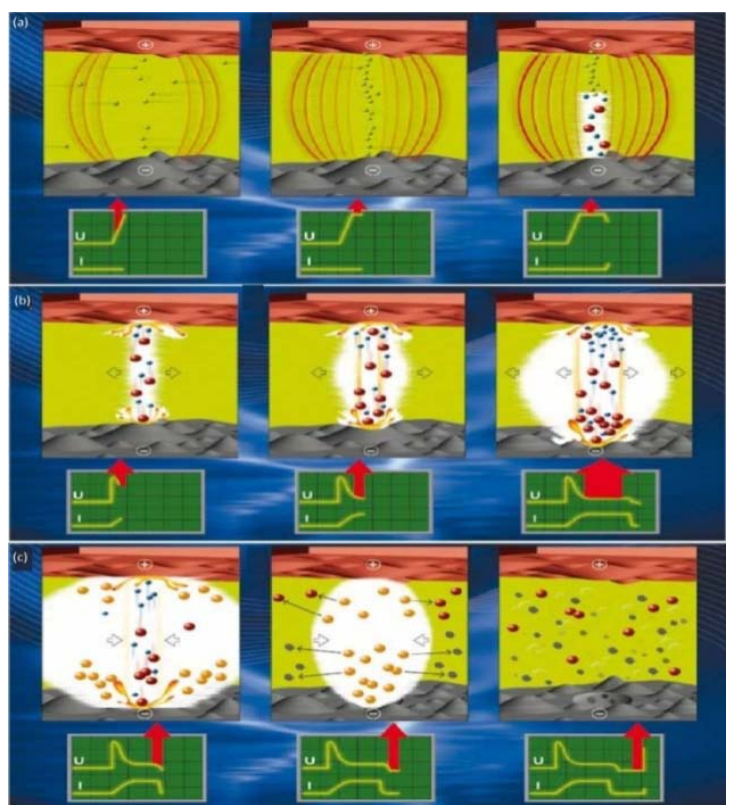

Figure 2: Sketch showing working of EDM (a) bridging of ions, (b) discharge and it's expansion and (c) crater formation

This results in the localized heating of the dielectric and formation of bubble of vapour from the dielectric liquid. Dissociated gases expand and the dynamic plasma pressure rises to as much as $1 \mathrm{kbar}$, because the surrounding dense liquid dielectric restricts the plasma growth [2]. This in turn increases the local pressure and temperature of the workpiece and this result in the melting of workpiece material and some of it moves out in form of debris.Gas bubble formed in discharge process plays an important role in removing molten materials from discharge gap [49]. Tool geometry and tool polarity also play a decisive role in the working of the machine [87].

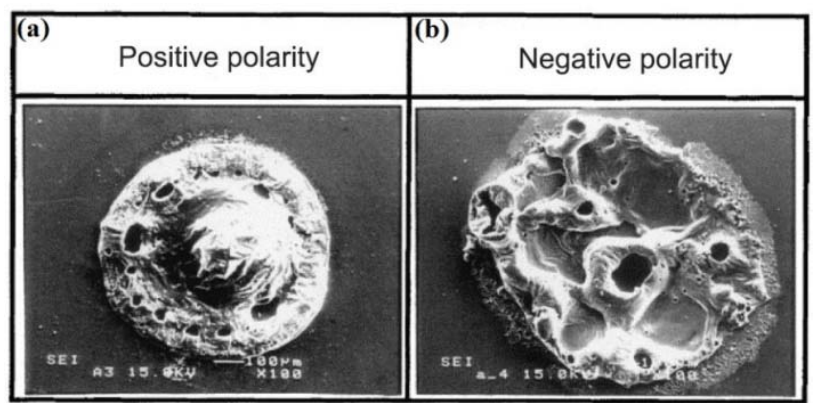

Figure 3: Image of crater formed (a) with positive polarity and (b) with negative polarity of tool [87]

\section{Types of Hybrids}

\subsection{WEDM}

WEDM is a kid brother of EDM. These are not new and came into existence in 1960's. These were inspired from the vertical EDM. The first EDM machine that used a wire as an electrode became commercially available in 1967 developed by USSR. The tool was replaced by thin wire which never touched the workpiece. In mid 1970s, when D. H. Dulebohn (1974) used optical line follower system to control the path of the wire in WEDM its popularity grew rapidly [26]. WEDM became a practical and manageable technique when later the first Computer Numerical Control (CNC) wire EDM machine was developed in 1976[26].

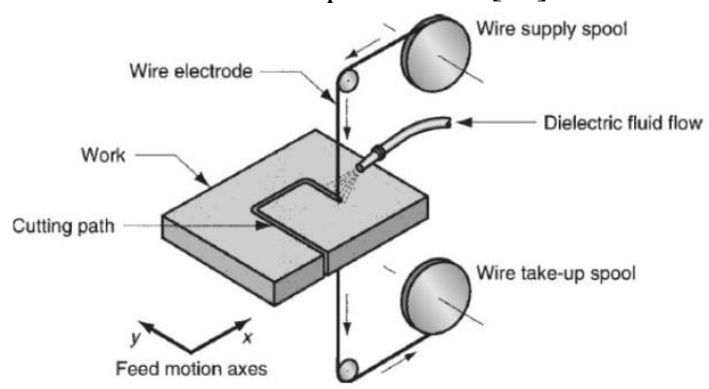

Figure 4: WEDM Setup

Since then brass, zinc coated brass, tungsten, copper have been used as the wire for tooling. Hybrids of WEDM in the form of WEDG and WECG have also evolved over a period of time and are used for finishing micro-parts. Mu-Tian Yan et al (2002) developed a closed loop wire tension control system to improve the accuracy [22]. Albert Wen-Jeng Huse et al (2004) carried out precision tapering of curved surface and worked on contouring accuracy [25]. R. Ramakrishnan et al (2008) developed an ANN model to predict and select the best parameters for cutting for Inconel 718 using CNC_WEDM [32]. Kinoshita et al developed a monitoring and control system to prevent wire-breakage [26]. Various other authors like M.T. Yan et al [26,55] and Y.S. Liao et al [26,49], I. Beltrami et al [26] and D. F. Dauw et al [26], F.L. Luo et al [20,26] and P.W. Wang et al [49] have played a great role in improving the machining process by studying the wire-breakage, wire-lag and wire- vibration and wiretension respectively.P.W. Wang et al (2013) designed a wire transport mechanism with active feed mechanism and multilayer damped vibration absorber to control wire tension and increase the precision [49]. Mihir S. Rana et al (2015) carried out WEDM using oxygen as dielectric and used ANN to optimise the process [69].WEDM could be used to produce 3D rotational surfaces with minimized number of trial setups using algorithm and automation[48].

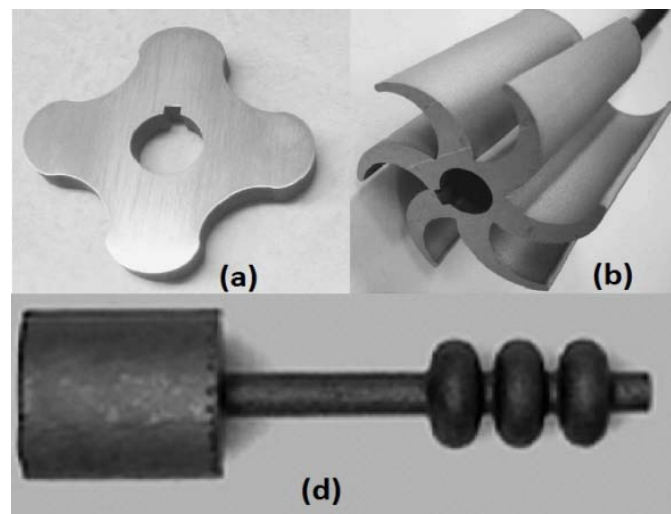

Figure 5: Images of complex 3D components fabricated using WEDM [25,40]

\subsection{Micro EDM}

The Pioneering history of micro-EDM goes back to 1960's at Phillips lab in Netherlands but there is no documentation. Takeshi Masaki et al (1990)developed a micro machining method and produced micro holes and shafts of $5 \mu \mathrm{m}$ with submicron precision accuracy and using the same developed 


\section{International Journal of Science and Research (IJSR) ISSN (Online): 2319-7064 \\ Index Copernicus Value (2015): 78.96 | Impact Factor (2015): 6.391}

a prototype air turbine of $2.2 \mathrm{~mm}$ capable of rotating at 1000rpm [6,9,17].T. Huguchi et al (1991) developed a pocket size EDM machine which was $18 \times 14 \times 68 \mathrm{~mm}$ with feeding step variable from 0.02 to $0.6 \mu \mathrm{m}[7,9,17]$. H. Morita et al (1995)developed direct drive method with step mode and hybrid mode to control the thin electrode and achieved promising increased MRR with hybrid mode [9]. Some researchers were exploring the use of LIGA made electrodes. Array of 200 holes was machined in 5 minutes which was 30 times faster than drilling a single hole at a time. A lot of research has been carried out in improving the shape complexity of micro EDMed parts [17]. Today best microEDM systems prepare their tools using WEDG. K. P. Rajurkar et al (2000) wielded CAD/CAM to 3D Micro EDM [18]. B.H. Yan et al (2002) used ultrasonic assisted micro EDM for the drilling of holes on the borosilicate glass and found that slurry concentration plays an important role [21]. C. Diver in 2004used the micro EDM to drill tapered holes for industrial application. C.C. Kao et al (2008) worked on the fuzzy logic control of micro drilling and found that multiinput controller is better than single-input controller and its application resulted in the increased stability and efficiency of the process [31].

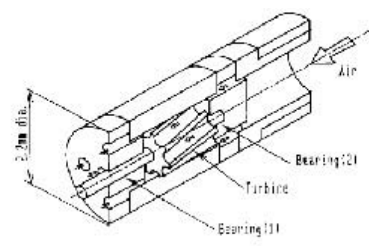

(a)

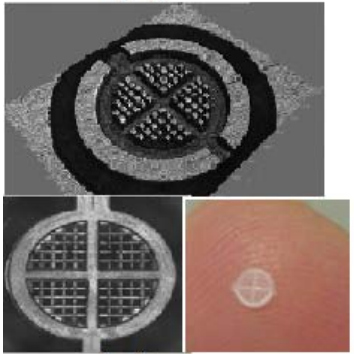

(c)

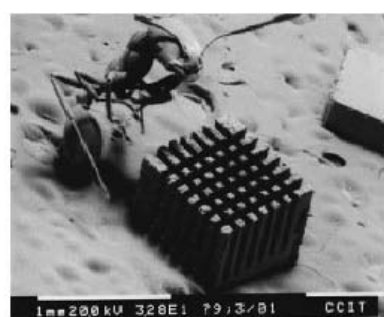

(b)

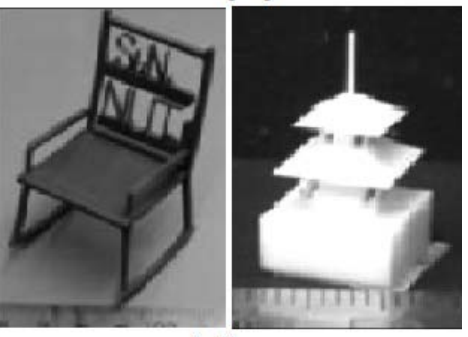

(d)
Figure 6: Images of components fabricated using micro EDM (a) schematics of micro air turbine [6], (b) SEM image of micro slit [87], (c) micro filter [85] and (d) chair and temple fabricated using micro WEDM [40]

Takashi Endo et al (2008) also used vibration assisted micro EDM and found that there was remarkable reduction of machining time if vibrations are applied perpendicularly and also the process becomes more stable [33]. B. Shao in 2015 carried out modelling of the crater formation in Micro EDM. Xuejie Guo et al (2013) proposed a theoretical model for calculating the planetary motion velocity of electrode to achieve better MRR in micro EDM drilling [52]. Al-Ahmari et al (2015) used laser assisted micro EDM for machining of Nickel-Titanium-Based Shape Memory Alloy and achieved amazing results [67].

\subsection{ECDM}

RudrofD.W. in 1957 published a work "Principles and Applications of Spark Machining" which laid the foundation of electrochemical discharge machining $[3,4]$. Kurafu H. et al (1968) carried out electro-chemical discharge drilling for drilling micro holes on glass [91].Machining speed of ECDM may be 5 to 50 times higher than that conventional EDM. Applied voltage, concentration of electrolyte and the temperature of cell are the most significant factors of machining. J. A. McGeough et al (1983) studied the relative effect of spark erosion and electro-chemical dissolution in arc machining and found that MRR is higher than that achieved in ECM or EDM individually [3].Crichton I.M. et al (1985) proposed that material removal in ECDM of conductive materials is due to combined effect of electro chemical dissolution and electric discharge [4,13]. Tokura H. et al (1989) and Jain V.K. (1997) observed that in case of non conductive materials chemical etching and spalling are responsible for material removaland also proposed "Valve theory" for calculating the MRR using finite element method [13,91]. Zhidong Liu et al (2015) carried out mist jet ECDM of brittle insulating Al2O3 ceramic [70]. Sanjay K. Chak (2016) carried out the electrochemical drilling with spark assistance and observed that pulsating current helped to improve the MRR [91]. Parveen Kumar Saini et al (2016) machined the E-Glass-Fibre-Epoxy Composite using ECDM and noticed that electrolytic concentration plays $76.38 \%$ contribution in MRR and supply voltage $20.57 \%$ [84].

\subsection{Vibration Assisted EDM}

Ultrasonic vibrations when applied to the EDM process they help to improve the MRR, surface texture, reduce arcing and increase the process stability [86,41]. D. Kremer et al (1989) studied the effect of ultrasonic vibrations on EDM and provided the inceptive work on UAEDM and reported that the pressure drop caused by the to and fro motion of the electrode helped to increase the MRR especially in finishing process and had positive influence on the machined surface $[5,7,20]$.Comparatively analysed work published by T.C. Lee et al(1998) provides introductory work on vibration assisted EDM. During the study ultrasonic machine was supplied with the DC power source with its positive pole connected to the workpiece and negative pole to the tool electrode. Experimental results also show that the MRR was little more than just the sum of ultrasonic machining and EDM and SR was less than that of EDM [15].Q.H. Zhang et al (2002) contributed to the ultrasonic vibration assisted EDM in gas and found that UAEDM produced higher MRR as compared to conventional dry and wet EDM and oxygen supply helped to enhance the MRR [20,39].B.H. Yan et al (2002) and Takashi Endo et al (2008) used vibrations to micro machine the borosilicate glass and brass respectively $[21,33]$.
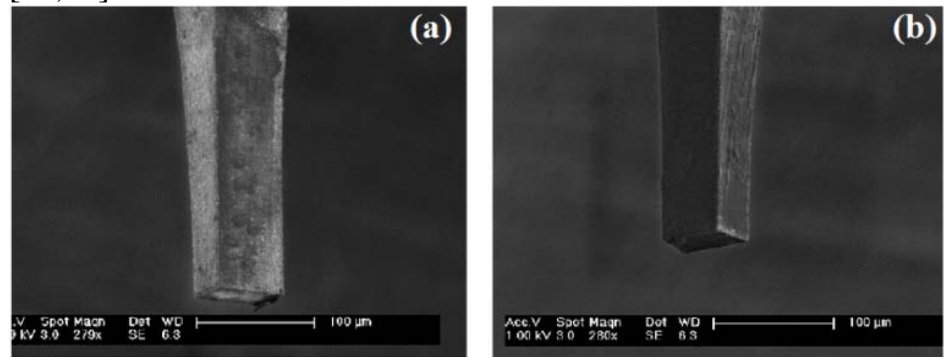

Figure 7: Image of square shaft machined using EDM (a) without vibration and (b) with vibration [33] 


\section{International Journal of Science and Research (IJSR) \\ ISSN (Online): 2319-7064}

Index Copernicus Value (2015): 78.96 | Impact Factor (2015): 6.391

M.G. Xua et al (2009) carried out vibration assisted dry EDM of cemented carbide YT15 with copper electrode and found that evaporation, spalling, oxidation, pressure and vibration helped to remove the material [38]. M.P. Jahan et al (2010) carried out a lot of work on the process modeling, optimization and simulation and found that the vibrations helped to improve the SR, process stability and MRR [41]. M Goiogana et al (2016) used pulsed UAEDM for the finishing process and achieved lesser surface roughness and increased homogeneity [78]. Y.C. Lin et al (2016) investigated the characteristics of hybrid dry EDM with assisted vibrations and abrasive jet and results showed that MRR, TWR and SR increased and the surface integrity reduced with increase of recast layer thickness and micropores [79].

\subsection{PEDM}

A. Erden et al (1980) studied theoretically and experimentally the effect of impurities in dielectric medium by artificially adding copper, aluminium, iron and carbon partials to the dielectric and found improvement in breakdown characteristics of kerosene as working fluid and increased MRR [17]. M.L. Jeswani et al (1981) added 4g/l graphite powder to kerosene and found that MRR increased by $60 \%$ and TW reduced by $15 \%[1,11,17,29]$. H. Narumiya et al (1989) used Al and graphite powder and achieved SR less than $2 \mu \mathrm{m}[19,29]$. Q.Y. Ming et al (1995) studied the effect of powder addition to kerosene and found that additives could increase the micro hardness, electrode gap and make the discharge current more even [11]. Y.Uno et al (1997-98) added Si powder and achieved glossier surface and then using Ni powder he deposited abrasion resistant layer on the surface of Al-Bronze [19,29]. Later Y.F. Tzeng et al (2001) and W.S. Zhao et al (2002) studied the effect of powder and its application for rough machining respectively and achieved inspiring results. During same year K. Furutani et al (2001) used PEDM to deposit layer of TiC to increase the hardness of machined surface $[7,19,29]$ and a layer of lubricant on carbon steel respectively[71]. H. Marashi et al (2015) employed the nano Ti powder to enhance the surface characteristics of the AISI D2 steel [71] whereas Naveen Beri et al (2014) used PM processed CuW electrodes to modify the surface quality of Inconel 718 and observed that metal transfer occurred from the electrode to the workpiece and the micro hardness of the surface increased [55]. G. Talla et al (2015) carried out PEDM of Al/Al2O3 MMC composite using aluminium suspended in kerosene and achieved better MRR and SR as compared to traditional EDM process [64]. M. Kolli et al (2015) has used graphite powder with surfactant in machining of titanium alloy and found that it reduced SR, increased MRR and reduced the thickness of recast layer [68].

\subsection{Magnetic field assisted EDM}

Y.C. Lin et al (2008) studied the machining parameters of magnetic assisted EDM and found that it helped to increase the effective discharge forms and produced even surface with increased stability of the process $[35,57,54]$ and then again next yearY.C. Lin et al (2009) optimized the process parameters for machining of SKD 61 using Grey relation and Taguchi approach and found that topography of machined surface improved when machined using magnetic assistance [24,54].

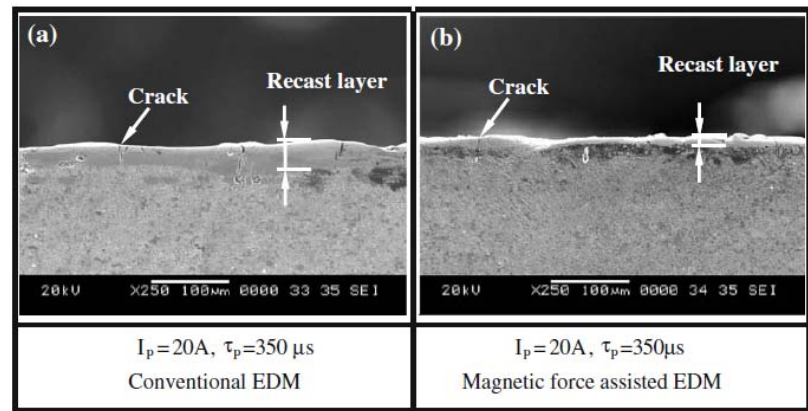

Figure 8: Cross sectional image of EDMed surface with (a) conventional EDM and (b) magnetic force assisted EDM [35]

Ken Heinz et al. (2011) observed that when assisted magnetic field is applied to the non-magnetic materials (Grade 5 Titanium) while performing $\mu$-EDM with tungsten wire Lorentz forces formed there resulted in the development of mechanical effect on the melt pool to aid in increasing material removal. It was observed that when the directional current was made to flow through the workpiece it generated Lorentz force in the melt pool.These forces helped to improve the MRR by over $50 \%$ and erosion efficiency improved by 54\% [45]. S. Joshi et al (2011) performed dry EDM in pulsating magnetic field and found that when the pulsating magnetic field is applied tangential to the electric field in dry EDM using oxygen gas and copper electrode then a maximum of $130 \%$ increase in MRR is observed whereas the TWR remained almost negligible [46].Y.C. Lin et al (2014) studied the effect of the magnetic assisted EDM with ultrasonic vibrations [58,79]. R Teimouri along with Hamid Baseri (2014) also played an important role in studying the effect of the rotating magnetic field dry EDM and applied continuous ant colony optimization technique [56]. Ahad Gholipoor et al (2014) investigated the effect of magnetic field on the near dry EDM process and found that magnetic field improves the debris flushing, remelting and sticking of debris to machined surface reduces, TWR increased and surface integrity improves [53].

\section{Material}

Instituted with the machining of tungsten [1,2,14] with the advancement of the Material Science and upcoming of the super hard materials like ceramics, MMC, sintered materials, nimonics and alloys the process of EDM slowly and steadily moved towards other materials. With the development of carbides and ceramics the conventional methods of machining failed and with the development of nonconductive super-hard traditional EDM process also failed. This resulted in the development of assisting electrode method of EDM [36,37]. Y. Fukuzawa et al (2009) carried out 3D machining of insulated ceramic (sintered $\mathrm{ZrO} 2$ 20\%Al2O3) and found that the tool material transferred from the tool to workpiece and the bending strength was inversely propositional to the SR [40].This method helped in the development of machining of various non-conductive materials with very limited limitations. To increase the conductivity of the materials PM process and sintering are employed. Even powered metal, carbon nano tubes and nano 


\section{International Journal of Science and Research (IJSR) \\ ISSN (Online): 2319-7064}

Index Copernicus Value (2015): 78.96 | Impact Factor (2015): 6.391

graphene molecules are added to enhance the conductivity and machine using EDM [50].

\section{Tool}

Conductive tool is imperative for EDM. A non-conductive workpiece could be machined but tool has to be conductive. Inaugural tools were solid made up of tungsten, copper, brass and graphite. Aboriginal change that tools met was in their shape. To achieve higher MRR and better flushing hollow tools came into existence. M. Kunieda et al (1991,1997) used hollow electrodes to attain increased MRR and improved flushing $[8,12]$.
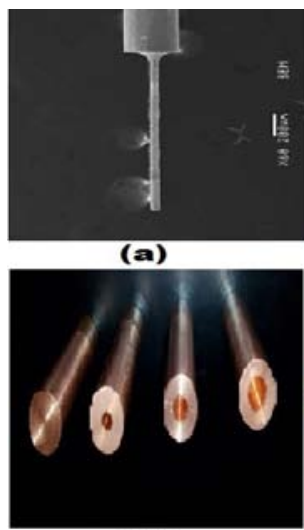

(c)

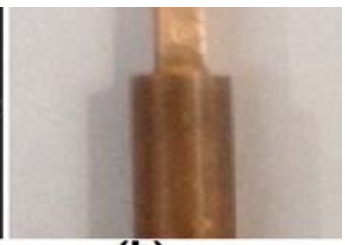

(b)

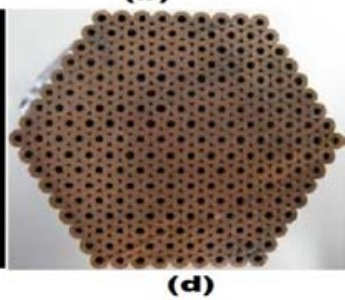

Figure 9: Images of different types of electrodes (a) micro electrode [52], (b) solid copper electrode [83], (c) hollow

copper electrodes [89] and bundled electrode [44]

M. Kunieda et al (2000) developed multi-spark electrode and its circuit and found that this resulted in the increase of over all MRR and energy efficiency, tool wear ratio decreased and there was no significant improvement in SR [16]. The most significant change was development of WEDM where tool transformed into thin wire $[15,84,26,20]$. EDM tool leaves very image on the workpiece and hence tools with mirror shapes of the final product are fabricated so that product could be developed in a single run. Mesh, disk, sheet, wire, tubular and PM processed electrodes are fabricated and used as per requirement. For the machining of non-conductive workpieces assisted electrode method was fostered where a thin mesh or sheet of conductive material is wrapped over the workpiece to assist the initiation of EDM process generally inside hydrocarbon oil $[39,34]$. Lin Gu et al (2011) suggested the use of bundled electrodes to reduce tooling time and cost and found that process could be EDM performed with very high efficiency if high peak current is used with multi hole internal flushing [44]. M.P.Samule and P.K. Philip in 1996ignited a new idea of the use of powdered metallurgy processed electrodes[14]. Tsai et al (2003) investigated the use of copper-chromium sintered electrodes and achieved machined surface with lesser micro cracks. Kumar et al (2009) reported the transfer of tool material to the workpiece under specific machining conditions and this laid the foundation of the surface treatment using PM processed electrodes.

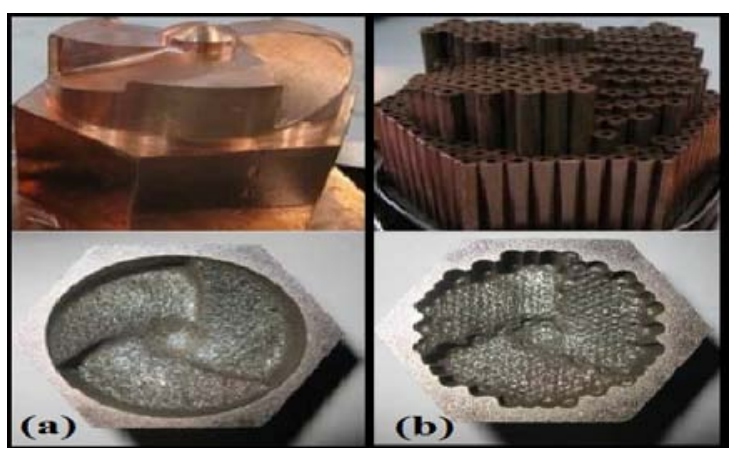

Figure 10: Image of rough machined workpiece with (a) conventional tool and (b) tool prepared by rapid tooling [44]

Murray et al and Naveen Beri et al (2014) published works on the surface treatment and enhancing the surface wear and corrosion properties using the PM processed electrodes[67].

\section{Dielectric}

In 1940 Dr. Boris Lazarenko and Dr. Natalya Lazarenko, were the first to propose the decisive role of the dielectric fluid and used non-conductive fluid as dielectric[1]. Since then various mineral oils, kerosene, mineral seals oils and transformer oils most of them from organic origin had been used.

\subsection{Liquid Dielectrics/Wet EDM}

Jeswani et al (1981) first time conducted EDM in distilled water and compared it with kerosene and found that at higher pulse energy range the MRR and SR improved and suggested that distilled water could be used for rough machining where accuracy is not requisite [2,28]. $\mathrm{T}$. Masuzawa et al (1983) published a work on water based dielectrics for EDM [8,10,87]. Since then distilled water, deionized water and tap water had been used by various researchers as dielectric[2,82,87,101].

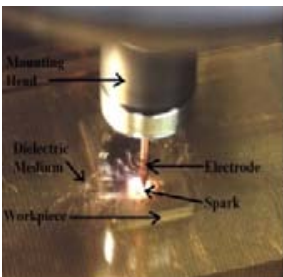

(a)

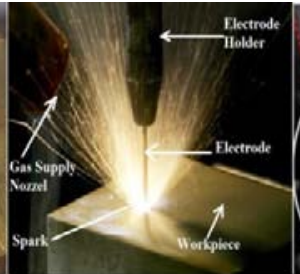

(b)

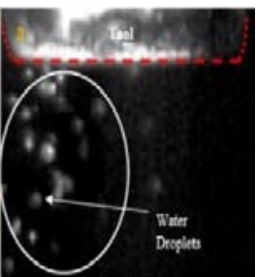

(c)
Figure 11: Images of (a) wet EDM, (b) dry EDM and (c) near dry EDM [74]

Sivapirakasam et al (2011) found that hazardous gases like aerosol are produced when EDM is carried out in hydrocarbons and on other hand Koeing et al (1987) and Liu et al (2010) found from their experiments that water is a poor performing, unsatisfactory and unfavourable dielectric with respect to the required outcomes as compared to the oil based dielectrics [70]. Y. Zhang et al (2014)carried out comparative analysis of five different dielectric which included water in oil emulsion as one of them and found that due to higher density of emulsion higher pressure of spark could be sustained for longer period which increased the MRR [54]. Murahari Kolli et al (2015) used surfactant along with the dielectric and found that this helped to achieve 


\section{International Journal of Science and Research (IJSR) ISSN (Online): 2319-7064 \\ Index Copernicus Value (2015): 78.96 | Impact Factor (2015): 6.391}

improved MRR and reduced TWR and SR [87]. Janak B. Valaki et al (2016) proposed that to adapt ISO-14000 standards, it was essential to apply sustainable manufacturing criteria in production and proposed the use of Jatropha curcas oil based bio dielectric for EDM[77].

\subsection{Gaseous Dielectric/Dry EDM}

Y. Kimoto et al (1960) suggested the supply of oxygen into the electrode gap to create an oxide layer on the electrode and increase its electron emission and in 1985 a paper published by NASA "Inert-Gas Electric-Discharge Machining" laid the foundation of dry EDM [8,34]. M. Kunieda et al (1997) carried out dry EDM using air and oxygen and found that air velocity, oxygen concentration and thinner walled tubular electrodes favoured the increase in machining efficiency[12,20]. Q.H. Zhang et al (2002) contributed to the dry EDM by performing it with ultrasonic vibration assistance and study resulted into production of higher MRR as compared to conventional dry and wet EDM and oxygen supply helped to enhance the MRR [20,39]. M. Kunieda et al (2003) carried out the high speed dry EDM milling using air and oxygen and found that high MRR could be achieved by machining in quasi-explosive mode and also found that suction of gas instead of jetting provides better results with sharper edges $[23,24]$.

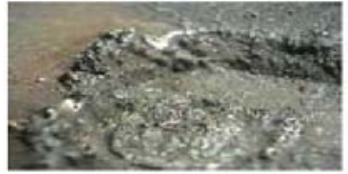

Jetting (air)

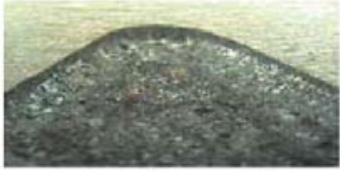

Intake (air)

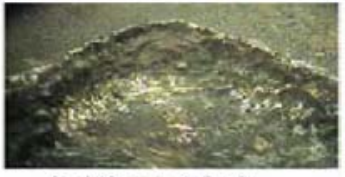

Jetting $\left(\mathrm{O}_{2}\right)$

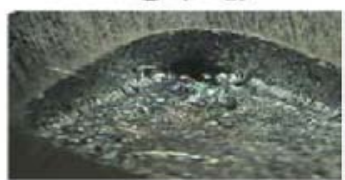

Intake $\left(\mathrm{O}_{2}\right)$
Figure 12: Image showing effect of jetting and intake of dielectric on edges [23]

ZhanBo Yu et al (2003) carried out dry EDM of cemented carbides and discovered that higher machining speed in 3D milling of cemented carbides could be achieved [24]. M.G. Xua et al (2009) carried out the vibration assisted dry EDM of cemented carbides and found that evaporation, spalling, oxidation, pressure and vibration helped to remove the material [38]. P. Govindan et al (2010) also studied the characteristics of dry EDM and found that current, voltage and rotation speed effected MRR (with 95\% confidence)[42]. P. Govindan et al (2010) carried out EDM helium and found that pressure was the main regulating factor with surface having glowing appearance and fewer micro cracks[43]. S. Joshi et al (2011) performed dry EDM in pulsating magnetic field and found that using oxygen gas and copper electrode then a maximum of $130 \%$ increase in MRR is observed whereas the TWR remained almost negligible [46,51].Saman Fattahi et al (2015) carried out dry EDM of M35 in air, nitrogen and air-argon mixture and found that highest MRR was achieved ( $3.77 \mathrm{~mm}^{3} / \mathrm{min}$ ) using air-argon mixture while nitrogen provided the best surface finish [59]. Yang Shen et al (2015) performed a high speed dry EDM and achieved MRR of $5162 \mathrm{~mm}^{3} / \mathrm{min}[65,75]$. M. S. Rana et al (2015) carried out WEDM using oxygen as dielectric and used ANN to optimise the process [69].Eckart Uhlmann et al (2016) carried out comparative analysis of dry an wet EDM and suggested oxygen for rough machining, de-ionized water for finishing and argon for sharper edges [72].Y.C. Lin et al (2016) performed hybrid dry EDM (vibrations and abrasive jet) and achieved increased MRR, TWR and SR with degraded surface integrity [79]

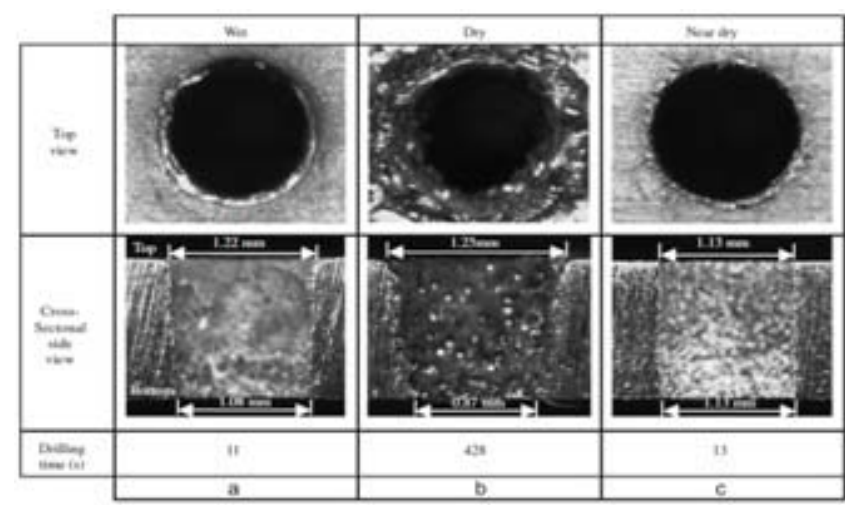

Figure 13: Images of (a) wet EDM, (b) dry EDM and (c) near dry EDM [74]

\subsection{Binary Phase Dielectric/ Near Dry EDM}

T. Tanimura et al (1989) published "Development of EDM in the mist" which laid the foundation of the near-dry EDM and led to the use of binary phase dielectric medium $[8,12]$. M. Kunieda et al (1991) also supplied oxygen to the IEG and achieved additional MRR owing to the oxidation caused by the gas [8]. C.C. Kao et al (2007) carried out research on near-dry EDM and found that MRR is higher in case near dry EDM and sharper edges could be cut and also better flushing reduced the debris deposition near the crater as compared to the wet EDM [28,31].

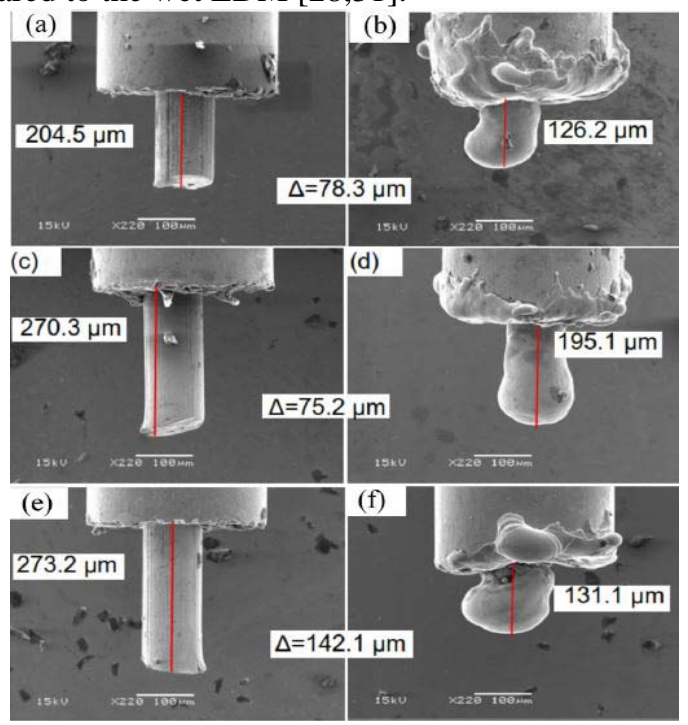

Figure 14: SEM images of tool electrodes before and after five discharges (a, b) wet-EDM; (c, d): spray-EDM and (e, f) dry-EDM [60]

J. Tao et al (2008) carried out EDM in a medium of kerosene-nitrogen and achieved a mirror like surface finish and also carried out a comparative investigation of dry and near dry electric discharge milling and suggested near dry EDM is benign for finishing process [34]. Ahad Gholipoor 


\section{International Journal of Science and Research (IJSR) \\ ISSN (Online): 2319-7064}

Index Copernicus Value (2015): 78.96 | Impact Factor (2015): 6.391

et al (2015) carried out comparative study of wet, dry and near dry EDM of SPK steel and suggested wet EDM for rough machining and near dry EDM for finishing [57]. Arvind Pattabhiraman et al (2015) studied the near dry EDM using atomized spray of EDM oil and suggested that in spray EDM discharge energy increased by $37 \%$ and volume of material removed increased by 78\% [60]. Krishnakant Dhakar et al (2016) utilized glycerin in near dry EDM and achieved promising results owing to high viscosity of the glycerin and better surface finish [74]. Y. Shen et al (2016) carried out a high speed near dry EDM of Ti6Al4V and achieved MRR of $648.22 \mathrm{~mm}^{3} / \mathrm{min}$ and found that pressure, droplet size, rotation speed, density and current play an important role in the process [76].

\section{Effect of Cryogenics in EDM}

Inceptive investigation related to the cryogenic treatment of the tool was conducted by A.A. Khan et al (2008) showed that the tool life on cryogenic treatment increased fourfold [30]. Suleiman et al (2009) discovered that the electrode wear of copper electrode could be decreased by $27 \%$ by cryogenic treatment and this also helped to improve the surface roughness. Rupinder Singh et al (2011) investigated the influence of cryogenic treatment on the process parameters and found that MRR,TWR and SR showed 60.39\%, 58.77\% and 7.99\% improvement respectively[55]. Srivastava et al (2012) carried out a comparative study on cryogenically treated tool using ultrasonic assisted EDM and found improvement of $27 \%$ in SR and $20 \%$ decrease in the tool wear[58]. L. Liqing in 2013 studied the effect of the cryogenically cooled workpiece in dry EDM and found that the MRR increased by 30-50\% approximately and SR value decreased by 1-10\%[51].Vinoth Kumar S. et al (2015) carried out comparative investigation of EDM process on AISI D2 tool steel using cryogenically treated electrode and found that there was 20\% decrease TWR and SR also improved by almost (19\%) same percentage [58]. Vaibhav Gaikwad et al (2016) calculated the optimized MRR of $7.0806 \mathrm{~mm}^{3} / \mathrm{min}$. for cryo-treated NiTi alloy [83].

\section{Surface Modification using EDM}

N. Mohri in 1988 carried out the study of surface modification in non-traditional machining processes [11]. J.P. Kurth et al (1995) proposed that EDM not only changes the surface but also the under lying surface along with it and he successfully coated steel with aluminum using EDM process [10]. Generally three layers are formed spattered, recast (white layer) and HAZ. Kurth et al (1998) found that white layer with increased carbon content with increased corrosion resistance and hardness is formed when process is carried out in hydrocarbon dielectric medium. Earlier the same thing was observed by Barash and Kahlon in 1965. Copper electrode fitted with two 5-mm diameter $\mathrm{ZrO} 2$ balls were used by Yan et al(2002) for the surface modification of $\mathrm{Al}-\mathrm{Zn}-\mathrm{Mg}$ alloy. Samule and Philip in 1996 were the first to use the PM processed electrodes and these electrodes played a great role in the surface modification [14,75]. Wang et al(2002) proposed the method of electric discharge coating (EDC) to modify the surface using powdered Ti in dielectric and boosted PEDM for surface treatment. Y.H. Guu et al (2005) carried out surface imaging of EDMed AISI D2 steel using atomic force microscopy technique and suggested use of low discharge energy for machining and polishing of EDMed surface before use [27]. Naveen Beri et al (2014) has also worked on the surface modification using PEDM and PM processed electrodes and found that a thin layer of few tens of micron could be deposited on the surface of Inconel 718 and micro hardness could also be improved [55].

\section{Assorted Unprecedented Ideas}

Kimoto et al (1960) reported that tool wear can be reduced, when the tool electrode is negative and a little oxygen gas is supplied into the gap because the oxide layer formed at cathode surface increases electron emission from the cathode [9]. M. Kunieda et al (2000) proposed the development of the multi spark electrodes. These electrodes were a kind of bundled electrodes insulated from each other. Opposite to the conventional EDM electrodes which produced single spark these electrodes produced multiple sparks at IEG and resulted in the increased MRR and reduced machining time[16]. Fuzhu Han and M. Kunieda (2004) designed a parallel spark EDM process. Power consumed by these electrodes was same as that of conventional electrodes but power generated at IEG was ' $n$ ' times ( $\mathrm{n}=$ number of sub-parts of electrode). M. Kunieda et al (2007) proposed that the rotation and planetary motion given to the electrode reduces the shorting and helps in flushing [15].Y. F. Luo et al. (2009) proposed that the shifting secondary discharge (SSD) is the main driving force for the expulsion of the molten material at cathode and less anodic metal expulsion was due to absence of SSD at anode[39].M. Kunieda oxygen when used to assist the EDM process increases the IEG and additional $5.6 \%$ power is generated because the gas reacts exothermically [9].In wet EDM carbon deposited on the tool and in dry EDM molten material from the workpiece deposited on the tool protect from tool wear[15].EDM has also helped to revolutionize the medical field. Petr Harcuba et al. (2012)investigated the properties of Ti-6Al-4V alloy after surface treatment by the electric discharge machining and found that treated surface of alloy provided a better substrate for bone cell growth and found that with higher peak currents mechanical properties degrade [47]. Rossella Surace et al (2016) designed and fabricated a polymeric micro filter for the use in biomedical sciences with the aid of EDM [85].Tassilo-Maria Schimmelpfennig et al (2015) carried out comapritive study of wet and dry EDM and came out with result that dry EDM has lower ringing effect and need sensitive tool drive with micro-piezoelectric actuators [61]. Shrikant Vidya et al (2015) observed that in $\mu E D M$ side discharge covering a segment of $120 \mathrm{deg}$ around the cylindrical electrode attributes to tool deflection, non-uniform spark gap, and jumping of discharges and rotation of tool electrode benefits significantly [62]. Hamid Baseri et al (2015) studied the effect of rotation of electrode, powder addition and magnetic field simultaneously and found that with the addition of $1 \mathrm{~g} / \mathrm{l}$ of $\mathrm{TiO} 2$ powder and application of magnetic field $(0.38 \mathrm{~T})$ could help to increase the MRR and also suggested that higher spark energy leads to conversion of large amount of electric energy to thermal energy and enhance MRR [63].Anand Prakash Dwivedi et al (2016) studied the effect of tool rotation on AISI D3 steel and found that when tool 


\section{International Journal of Science and Research (IJSR) \\ ISSN (Online): 2319-7064}

Index Copernicus Value (2015): 78.96 | Impact Factor (2015): 6.391

rotation was used MRR increased by 40\%, tool wear increased minimum by $13.5 \%$ and SR improved by $9-10 \%$ [73]. N. Flores Medina et al (2016) used isostatic graphite powder from milled molds for Electrical Discharge Machining (EDM) to increase the mechanical strength of the gypsum paste as compared to other conventional fillers [81]. Nirdesh Ojha et al (2016) found that the EDM treatment of the surface reduces the hardness and the flexural strength of the workpiece due to pertaining SR and proposed that SR could be reduced by polishing machining [82].

\section{Concluding Remarks}

In last 3 to 4 decades a lot of work has been done on improving the machining efficiency of the electric discharge machining. Parameter optimization, setup changes, dielectric use, ANNs, design changes and lot more has been endeavored. This has resulted in great deal of advancement in the machining process. Today we can achieve material removal rates as high as $5162 \mathrm{~mm}^{3} / \mathrm{min}$ which very high. But a very little work has been done to study the process in depth. Very little work has been done to understand the process as a whole. Very few models have been designed. Models for the discharge anomaly, crater formation, material removal and over all process are not verified, not reliable and incomplete or absent. Study of the effects of the physical properties of the dielectric such as viscosity, density and temperature on the bubble formation, pressure retention at spark location, material removal and flushing has not been studied thoroughly. In dry EDM gas mixing, penning effect and excitation energy of molecules and their effect on the EDM process still require deeper analysis. Hybrid EDM systems with multiple optimized variables will help to enhance the process. Moreover manufacturing shifting towards sustainable one under the guidelines of ISO 14000 standards there is a burning need of designing sustainable and eco-friendly EDM process. Powdered EDM, nano-technology implementations, sustainable dielectrics, electrode designs and computing models still require abysmal study.

\section{References}

[1] M. L. Jeswani, "Effect of Addition of Graphite Powder to Kerosene used as Dielectric Fluid in Electric Discharge Machining”, Wear, Vol. 70, pp. 133-139 (1981)

[2] M. L. Jeswani, “ Electric Discharge Machining in Distilled Water”, Wear, Vol. 72, pp. 81-88 (1981)

[3] J. A. McGeough, A. B. M. Khayry and W. Munro, "Theoretical and Experimental Investigation of Relative Effects of Spark Erosion and Electrochemical Dissolution in Electro Chemical Arc Machining”, Annals of the CIRP, Vol. 32/2/1983, pp. 113-118 (1983)

[4] I. M. Crichton and J. A. McGeough, "Studies of Discharge Mechanism In Electrochemical Arc Machining”, Journal Of Applied Electrochemistry, Vol. 15, pp. 113-119 (1985)

[5] D. Kremer, J. L. Lebrun, B. Hosari, A. Moisan, "Effects of Ultrasonic Vibrations on the Performances in EDM", Annals of the ClRP, Vol. 38/1/1989, pp. 199-202 (1989)

[6] Takeshi Masaki, Koichi Kawata and Takashisa Mauzawa, "Micro Electro Discharge Machining and its
Applications”, IEEE, Vol. CH2832-4/90/0000-0021, pp. 21-26 (1990)

[7] T. Higuchi, K. Furutani, Y. Yarnagata and K. Takeda, "Development of Pocket-size Electro-Discharge Machine”, Annals of the CIRP, Vol. 40/7/1991, pp. 203206 (1991)

[8] M. Kunieda and S. Furuoya," Improvement of EDM Efficiency by Supplying Oxygen Gas into Gap”,Annals of the CIRP, Vol. 4/7/1991, pp. 215-218 (1991)

[9] H. Morita, K. Furutani and N. Mohri, "Electrical Discharge Device with Direct Drive Method for Thin Wire Electrode”, IEEE, Vol. 0-7803-1965-6/95, pp. 7378 (1995)

[10] J.P. Kurth, L. Stevens, L. Froyen, B. Lauwers and K. U. Leuven, "Study of The White Layer of The Surface Machined by Die Sinking Electro Discharge Machining”, Annals of the CIRP, Vol. 44/1/1995, pp. 169-172 (1995)

[11]Q. Y. Ming and Y. H. Liu, "Powder Suspension Dielectric Fluid for EDM", Journal Of Material Processing Technology”, Vol. 52, pp. $44-54$ (1995)

[12] Masanori Kunieda and Masahiro Yoshida,” Electrical Discharge Machining in Gas”,Annals of the CIRP , Vol. 46/1/1997, pp. 143-146 (1997)

[13] V.K. Jain, P.M. Dixit and P.M. Pandey, "On the analysis of the electrochemical spark machining process", International Journal of Machine Tools \& Manufacture, Vol. 39, pp. 165-186 (1999)

[14] M. P. Samule and P. K. Philip, "Powder Metallurgy Tool Electrodes for Electric Discharge Machining”, International Journal of Machine Tools \& Manufacture, Vol. 37, pp. 1625-1633 (1997)

[15] T. C. Lee , J. H. Zhang and W. S. Lau,” Machining of Engineering Ceramics by Ultrasonic Vibration Assisted EDM Method”, Materials and Manufacturing Processes, Vol. 13, No.1, pp.133-146 (1998)

[16]M. Kunieda and Hideyuki Muto, "Development of Multi-Spark EDM", Annals of the CIRP, Vol. 49/1/2000, pp. 119-122 (2000)

[17] T. Masuzawa, "State of The Art of Micro-machining", Annals of the ClRP, Vol. Vol. 49/2/2000, pp. 473-488 (2000)

[18] K. P. Rajurkar and Z. Y. Yu, “3D Micro-EDM using CAD-CAM”, Annals of the ClRP, Vol. 49/1/2000, pp. 127-130 (2000)

[19] K. Furutani, A. Saneto, H. Takezawa, N. Mohri and H. Miyake, "Accretion of titanium carbide by electrical discharge machining with powder suspended in working fluid", Journal of the International Societies for Precision Engineering and Nanotechnology, Vol. 25, pp. 138-144 (2001)

[20] Q. H. Zhang, J. H. Zhang, J. X. Deng, Y. Qin and Z. W. Niu, "Ultrasonic Vibration Electric Discharge Machining in Gas", Journal of Material Processing Technology, Vol. 129, pp. 135-138 (2002)

[21]B.H. Yan , A.C. Wang, C.Y. Huang and F.Y. Huang, "Study of precision micro-holes in borosilicate glass using micro EDM combined with micro ultrasonic vibration machining”, International Journal of Machine Tools \& Manufacture, Vol. 42, pp. 1105-1112 (2002)

[22] M. T. Yan and P. H. Huang, "Accuracy improvement of wire-EDM by real-time wire tension control”, 


\section{International Journal of Science and Research (IJSR) \\ ISSN (Online): 2319-7064}

Index Copernicus Value (2015): 78.96 | Impact Factor (2015): 6.391

International Journal of Machine Tools \& Manufacture, Vol. 44, pp. 807-814 (2004)

[23] M. Kunieda, Y. Miyoshi and T. Takaya,’High Speed 3D Milling by Dry EDM”,CIRP Annals-Manufacturing Technology, Vol. 52, pp. 147-150 (2003)

[24] Y. ZhanBo, J. Takahashi and M. Kunieda, "Dry electrical discharge machining of cemented carbide", Journal of Material Processing Technology, Vol. 149, pp. 353-357 (2004)

[25] Albert Wen-Jeng Hsue and Hsin-Cheng Su, "Removal analysis of WEDM's tapering process and its application to generation of precise conjugate surface”, Journal of Material Processing Technology, Vol. 149, pp. 117-123 (2004)

[26] K.H. Ho, S.T. Newman, S. Rahimifard and R.D. Allen, "State of the art in wire electrical discharge machining (WEDM)”, International Journal of Machine Tools \& Manufacture, Vol. 44, pp. 1247-1259 (2004)

[27] Y.H. Guu, “AFM surface imaging of AISI D2 tool steel machined by the EDM process", Applied Surface Science, Vol. 242, pp. 145-150 (2005)

[28]C.C. Kao, Jia Tao and Albert J. Shih, "Near dry electrical discharge machining", International Journal of Machine Tools \& Manufacture, Vol. 47, pp. 22732281 (2007)

[29]H.K. Kansal, Sehijpal Singh and Pradeep Kumar, "Technology and research developments in powder mixed electric discharge machining (PMEDM)", Journal of Material Processing Technology, Vol. 184, pp. 32-41 (2007)

[30] A. A. Khan and Mirghani I. Ahmed, “ Improving Tool Life Using Cryogenic Cooling”, Journal of Material Processing Technology, Vol. 196, pp. 149-154 (2008)

[31] Chen-Chun Kao, Albert J. Shih and Scott F. Miller," Fuzzy Logic Control of Microhole Electrical Discharge Machining”, Journal of Manufacturing Science and Engineering, ASME, Vol. 130, 064502:1-064502:6 (2008)

[32] R. Ramakrishnan and L. Karunamoorthy, "Modeling and multi-response optimization of Inconel 718 on machining of CNC WEDM process", Journal of Material Processing Technology, Vol. 207, pp. 343-349 (2008)

[33] Takashi Endo, Takayuki Tsujimoto and Kimiyuki Mitsui, " Study of vibration-assisted micro-EDM-The effect of vibration on machining time and stability of discharge”, Precision Engineering, Vol. 32, pp. 269277 (2008)

[34] J. Tao, Albert J. Shih and Jun Ni, "Experimental Study of Dry and Near Dry Electric discharge Milling Processes”, Journal of Manufacturing Science and Engineering, Vol. 130, pp. 011002:1-011002:9 (2008)

[35] Y. C. Lin and H. S. Lee, "Optimization of machining parameters using magnetic-force-assisted EDM based on gray relational analysis”, International Journal of Advanced Manufacturing Technology, Vol. 42, pp. 1052-1064 (2009)

[36] Guanqun Deng, Yongfeng Guo, Zesheng $\mathrm{Lu}$ and Jicheng Bai," A Novel Pulse Power Supply for Insulated Ceramics by HS-WEDM”, IEEE, ISBN: 9781-4244-2487-0 (2009)

[37] S. Lopez-Esteban, C.F. Gutierrez-Gonzalez, G. MataOsoro, C. Pecharroman, L.A. Diaz1, R. Torrecillas and
J.S. Moya, "Electrical Discharge Machining of Ceramic/Semiconductor/Metal Nanocomposite”, Scripta Materialia, Vol. 63, pp. 219-222 (2010)

[38] M.G. Xu, J.H. Zhang, Y. Li, Q.H. Zhang and S.F. Ren, "Material removal mechanisms of cemented carbides machined by ultrasonic vibration assisted EDM in gas medium”, Journal of Material Processing Technology, Vol. 209, pp. 1742-1746 (2009)

[39] Y. F. Luo and Jia Tao, "Metal Removal in EDM Driven by Shifting Secondary Discharge", Journal of Manufacturing Science and Engineering, ASME, Vol. 131, 031014:1-031014:7 (2009)

[40] Yasushi Fukuzawa, Naotake Mohri, Hiromitsu Gotoh and Takayuki Tani, "Three-dimensional machining of insulating ceramics materials with electrical discharge machining”, Elsevier, Transactions of Nonferrous Metals Society of China, Vol. 19, pp. 150-156 (2009)

[41] M. P. Jahan, T. Saleh, M. Rahman and Y. S. Wong, "Development, Modeling, and Experimental Investigation of Low Frequency Workpiece VibrationAssisted Micro-EDM of Tungsten Carbide”, Journal of Manufacturing Science and Engineering, ASME, Vol. 132, 054503:1- 054503:8 (2010)

[42] P. Govindan and Suhas S. Joshi, "Experimental characterization of material removal in dry electrical discharge drilling”, International Journal of Machine Tools \& Manufacture, Elsevier, Vol. 50, pp. 431-443 (2010)

[43] Govindan Puthumana, Rahul Agarwal and Suhas S. Joshi, "Experimental investigation on dry electrical discharge machining using helium gas", Proceedings of the 3rd International \& 24th AIMTDR, pp. 1-6 (2010)

[44] Lin Gu, Lei Li, Wansheng Zhao and Kamlakar P. Rjaurkar, “An Efficient and Economical Rapid-Tooling Method for Die-Sinking Electrical Discharge Machining”, Journal of Manufacturing Science and Engineering, ASME, Vol. 133, 051004:1- 051004:7, (2011)

[45] Ken Heinz, Shiv G. Kapoor, Richard E. DeVor and Vijay Surla, “An Investigation of Magnetic-FieldAssisted Material Removal in Micro-EDM for Nonmagnetic Materials”, Journal of Manufacturing Science and Engineering, ASME, Vol. 133, 021002:1021002:9 (2011)

[46] S. Joshi, P. Govindan, A. Malshe and K. Rajurkar, "Experimental characterization of dry EDM performed in a pulsating magnetic field”, CIRP Annals Manufacturing Technology, Vol. 60, pp. 239-242 (2011)

[47] Petr Harcuba, Lucie Bacakova, Josef Strasky, Marketa Bacakova, Katarina Novotna and Milos Janecek, "Surface treatment by electric discharge machining of Ti-6Al-4V alloy for potential application in orthopedics", Journal of the Mechanical Behavior of Biomedical Materials, Elsevier, Vol. 7, pp. 96-105 (2012)

[48]Zhi Yang, Richard A Wysk and Sanjay Joshi, "Setup Planning Automation for Six-Axis Wire Electrical Discharge Machining”, Journal of Manufacturing Science and Engineering, ASME, Vol. 134, 021009:1021009:10 (2012)

[49] P. W. Wang and C. S. Yang, "Analysis and Design of Wire Transport System in Microwire-Electronic 


\section{International Journal of Science and Research (IJSR) \\ ISSN (Online): 2319-7064}

Index Copernicus Value (2015): 78.96 | Impact Factor (2015): 6.391

Discharge Machining”, Journal of Micro- and NanoManufacturing, ASME, Vol. 1, 021006:1-021006:9 (2013)

[50] D.Hanaoka, Y.Fukuzawa, C. Ramirez, P. Miranzo, M.I.Osendi and M. Belmonte, "Electrical discharge machining of ceramic/carbon nanostructure composites”, Procedia CIRP, Elsevier, Vol. 6, pp. 95100 (2013)

[51]L. Liqing and S. Yingjie, "Study of dry EDM with oxygen-mixed and cryogenic cooling approaches", Procedia CIRP, Elsevier, Vol. 6, pp. 344-350 (2013)

[52] Xuejie Guo, Zuyuan Yu, Zhongwei Lv, Jianzhong Li and Wataru Natsu, "Optimization of Planetary Movement Parameters for Micro-hole Drilling by Micro-Electrical Discharge Machining”, Journal of Micro- and Nano-Manufacturing, ASME, Vol. 1, 031007:1- 031007:5 (2013)

[53] Ahad Gholipoor, Hamid Baseri, Mohsen Shakeri and Mohammadreza Shabgard, "Investigation of the effects of magnetic field on near-dry electrical discharge machining performance", Proc IMechE Part B:J Engineering Manufacture, pp. 1-8 (2014)

[54] Yanzhen Zhang, Yonghong Liu*, Yang Shen, Renjie Ji, Zhen $\mathrm{Li}$ and Chao Zheng, "Investigation on the influence of the dielectrics on the materialremoval characteristics of EDM", Journal of Materials Processing Technology, Elsevier, Vol. 214, pp. 10521061 (2014)

[55] Naveen Beri, Sachin Maheswari, Chitra Sharma and Anil Kumar, "Surface Quality Modification using Powder Metallurgy Processed CuW Electrode during Electric Discharge Machining of Inconel 718”, Procedia Materials Science, Elsevier, Vol. 5, pp. 26292634 (2014)

[56] R. Teimouri and H. Baseri, "Optimization of magnetic field assisted EDM using the continuous ACO algorithm”, Applied Soft Computing, Vol. 14, pp. 381389 (2014)

[57] Ahad Gholipoor, Hamid Baseri and Mohammad Reza Shabgard, "Investigation of near dry EDM compared with wet and dry EDM processes", Journal of Mechanical Science and Technology, Springer, Vol. 29, pp. 2213-2218 (2015)

[58] Vinoth Kumar and Pradeep Kumar,” Experimental investigation of the process parameters in cryogenic cooled electrode in EDM", Journal of Mechanical Science and Technology, Vol. 29, pp. 3865-3871 (2015)

[59] Saman Fattahi and Hamid Baseri, "Analysis of dry electrical discharge machining in different dielectric mediums", Proc IMechE Part E: J Process Mechanical Engineering, pp. 1-16 (2015)

[60] Arvind Pattabhiraman, Deepak Marla and Shiv G. Kapoor, "Atomized Dielectric Spray-Based Electric Discharge Machining for Sustainable Manufacturing", Journal of Micro- and Nano-Manufacturing, ASME, Vol. 3, 041008:1- 041008:8 (2015)

[61] Tassilo-Maria Schimmelpfennig, Ivan Perfilov, Jan Streckenbach and Eckart Uhlmann, " Comparison of Conventional and Dry Electrical Discharge Machining", Applied Mechanics and Materials, Vol. 794, pp. 278284 (2015)
[62] Shrikant Vidya, Vijay, Swapan Barman, Aneissha Chebolu, Nagahanumaiah and Alok Kr. Das, "Effects of Different Cavity Geometries on Machining Performance in Micro-Electrical Discharge Milling", Journal of Micro- and Nano-Manufacturing, ASME, Vol. 3, 011007:1- 011007:10 (2015)

[63]Hamid Baseri and Samin Sadeghian, " Effects of nanopowder TiO2-mixed dielectric and rotary tool on EDM", International Journal of Advanced Manufacturing Technology, Springer, pp. 1-10 (2015)

[64] Gangadharudu Talla, Deepak Kumar Sahoo, S. Gangopadhyay and C.K. Biswas ," Modeling and multiobjective optimization of powder mixed electric discharge machining process of aluminum/alumina metal matrix composite", Engineering Science and Technology, an International Journal, Vol. 18, pp. 369373 (2015)

[65] Y. Shen, Y. H. Lin, Y. Z. Zhang, H. Dong, W. Sun, X. Wang, C. Zheng and Renjie Ji, "High-speed dry electrical discharge machining", International Journal of Machine Tools \& Manufacture, Elsevier, Vol. 93, pp. 19-25 (2015)

[66] Bharat C. Khatri, Pravin Rathod and Janak B Valaki, "Ultrasonic vibration-assisted electric discharge machining: A research review", Journal of Engineering Manufacture, pp. 1-12 (2015)

[67]A. Al-Ahmari, M. Sarvar Rasheed, Muneer Khan Mohammed and T. Saleh, "A Hybrid Machining Process Combining Micro-EDM and Laser Beam Machining of Nickel-Titanium Based Shape Memory Alloy”, Materials and Manufacturing Processes, Vol. 31, Issue 4 (2016)

[68] Murahari Kolli and Adepu Kumar, " Effect of dielectric fluid with surfactant and graphite powder on Electrical Discharge Machining of titanium alloy using Taguchi method", Engineering Science and Technology, an International Journal, Vol. 18, pp. 524-535 (2015)

[69] Mihir S. Rana, Dharmin M. Pavagadhi, Vijay A. Bhagora, Prof. B.C.Khatri and Prof. J.B.Valaki, "Process Optimization and Estimation of Oxygen Assisted Wire Electrical Discharge Machining Performance using Artificial Neural Network",International Journal for Scientific Research \& Development, Vol. 3, pp. 1457-1463 (2015)

[70]Zhidong Liu, Haoran Chen, Jianyuan Yu and Huijun Pan, "Machining characteristics of hard and brittle insulating materials with mist-jetting electrochemical discharge", International Journal of Advanced Manufacturing Technology, Vol. 79, pp. 815-822 (2015)

[71] H. Marashi, Davoud M. Jafarlou, Ahmed A.D. and Sarhan Mohd Hamdi, "State of the art in powder mixed dielectric for EDM applications”, Precision Engineering, Vol. 46, pp. 11-33 (2016)

[72] Eckart Uhlmann, Tassilo-Maria Schimmelpfennig, Ivan Perfilov, Jan Streckenbach and Luiz Schweitzer, "Comparative Analysis of Dry-EDM and Conventional EDM for the Manufacturing of Micro holes in Si3N4TiN", Procedia CIRP, ScienceDirect, Vol. 42, pp. 173178 (2016)

[73]Anand Prakash Dwivedi and Sounak Kumar Choudhury, "Effect of Tool Rotation on MRR, TWR and Surface Integrity of AISI-D3 Steel using Rotary 


\section{International Journal of Science and Research (IJSR) \\ ISSN (Online): 2319-7064}

Index Copernicus Value (2015): 78.96 | Impact Factor (2015): 6.391

EDM Process", Materials and Manufacturing Processes, Vol. 31, pp. 1-42 (2016)

[74] Krishnakant Dhakar, Akshay Dvivedi and Amit Dhiman, " Experimental investigation on effects of dielectric mediums in near-dry electric discharge machining", Journal of Mechanical Science and Technology, Vol. 30, pp. 2179-2185 (2016)

[75] Y. Shen, Y. Liu and W. Sun, "High-efficient Dry Hybrid Machining of EDM and Arc Machining", Procedia CIRP, ScienceDirect, Vol. 42, pp. 149-154 (2016)

[76] Yang Shen, Yonghong Liu, Wanyun Sun, Yanzhen Zhang, Hang Dong, Chao Zheng and Renjie Ji, " Highspeed near dry electrical discharge machining", Journal of Materials Processing Technology, Vol. 233, pp. 9-18 (2016)

[77] Janak B. Valaki, Pravin P. Rathod and C.D. Sankhavara, " Investigations on technical feasibility of Jatropha curcas oil based bio dielectric fluid for sustainable electric discharge machining (EDM)", Journal of Manufacturing Processes, Vol. 22, pp. 151160 (2016)

[78] M. Goiogana, J.A. Sarasua, J.M. Ramos, L. Echavarri and I. Cascon, "Pulsed ultrasonic assisted electrical discharge machining for finishing operation”, International Journal of Machine Tools \& Manufacture, Vol. 109, pp. 87-93 (2016)

[79] Yan-Cherng Lin, Jung-Chou Hung, Han-Ming Chow, A-Cheng Wang and Jyun-Ting Chen, " Machining Characteristics of a Hybrid Process of EDM in Gas Combined with Ultrasonic Vibration and AJM", Procedia CIRP, Vol. 42, pp. 167-172 (2016)

[80] Mudimallana Goud, Apurbba Kumar Sharma and Chandrashekhar Jawalkar, "A Review on Material Removal Mechanism in Electrochemical Discharge Machining (ECDM) and Possibilities to Enhance the Material Removal Rate”, Precision Engineering, Vol. 45, pp. 1-17 (2016)

[81] N. Flores Medina, M. Mar Barbero-Barrera and Rosa Bustamante, " Improvement of the properties of gypsum-based composites with recycled isostatic graphite powder from the milling production of molds for Electrical Discharge Machining (EDM) used as a new filler", Construction and Building Materials, Vol. 107, pp. 17-27 (2016)

[82] Nirdesh Ojha, Florian Zeller, Claas Mueller and Holger Reinecke, " The Effect of the Electrical Discharge Machining Process on the Material Properties of Nonconductive Ceramics", Journal of Micro- and Nano-Manufacturing, Vol. 4, 011007:1- 011007:5 (2016)

[83] Vaibhav Gaikwad, Vijay Kumar and S. Jatt, " Optimization of material removal rate during electrical discharge machining of cryo-treated NiTi alloys using Taguchi's method", Journal of King Saud University Engineering Sciences, Vol 28, pp. 11-17 (2016)

[84] Parveen Kumar Saini, Tarjeet Singh and Gagandeep Singh Dhindsa, "Micro Machining of E-Glass-FibreEpoxy Composite using Electro Chemical Discharge Machining”, IJEDR, Vol. 4, Issue 2, ISSN: 2321-9939 (2016)

[85] Rossella Surace, Vincenzo Bellantone, Gianluca Trotta, Vito Basile, Francesco Modica and Irene Fassi, "
Design and Fabrication of a Polymeric Microfilter for Medical Applications", Journal of Micro- and NanoManufacturing, ASME, Vol. 4, 011006:1- 011006:7 (2016)

[86]S. Tripathy and D.K. Tripathy, " Multi-attribute optimization of machining process parameters in powder mixed electro-discharge machining using TOPSIS and grey relational analysis", Engineering Science and Technology, an International Journal, Vol. 19, pp. 62-70 (2016)

[87] Gangadharudu Talla, S Gangopadhayay and CK Biswas, "State of the art in powder-mixed electric discharge machining: A review", Journal of Engineering Manufacture, Part B, pp. 1-16, doi: 10.1177/0954405416634265 (March 2016)

[88] Rupinder Singh and Bhupinder Singh, "Comparison of Cryo Treatment Effect on Machining Characteristics of Titanium Electric Discharge Machining”, International Journal Automotive and Mechanical Engineering, Vol. 3, pp. 239-248 (2011)

[89] Gupta Rahul, Bibave Pooja, Ashish, Kesarkar Rohit, Bari Prasad and Chauhan Santosh, "Optimization of Electrical Discharge Machining Process Parameters Using Flushing and Drilled Tool", International Research Journal of Engineering and Technology (IRJET), Vol. 3, pp. 1316-1320 (2016).

\section{Author Profile}

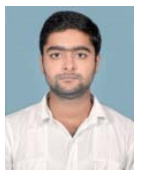

Vishal Pathania is M. Tech Scholar pursuing his degree from HPTU in Production Engineering and is working on his thesis at ISTC wing of CSIR-CSIO Chandigarh under the guidance of Senior-Scientist $\mathrm{Mr}$ Narinder Singh Jassal. His field of interest is nonconventional machining and currently working on electric discharge machining.

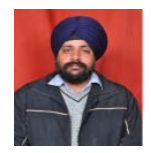

Narinder Singh Jassal is working as Senior-Scientist at CSIO-CSIR Chandigarh. He holds the position of the Principal of ISTC wing. He has worked on various conventional and non-conventional machining processes and published number of research papers. His main area of research has been EDM and conventional machining. He has guided many $\mathrm{M}$. Tech scholars and is an Educationist. 